\title{
Qualitative Research Approach in LIS Education: Comparative Methodology Study
}

\author{
Dr. Hesham Mohamed
}

\begin{abstract}
Libraries transformed in the past decade to focus on community needs. Accordingly, the library business model has been shifted from a service centered model that focuses on services for all users to a customer centered model that focuses on the patron's needs. Thus, studies in the field of Library and Information Science (LIS) have become focusing more on subjectivity rather than objectivity. Qualitative inquiry focuses on subjectivity to investigate human perceptions, feelings, thoughts regarding to either services they deliver or services they obtain. In contrast, quantitative inquiry focuses on objectivity to test hypotheses and measure services statistically.This comparative methodology study aims to differentiate between qualitative and quantitative research methods. Further, the research provided a comparison between phenomenological, case study, and grounded theory qualitative designs in which are mostly used in LIS education. The discussion in this research provided the LIS qualitative researchers with a clear guideline needed to measure and evaluate the trustworthiness of each qualitative research design.
\end{abstract}

\section{Introduction}

Library and Information Science (LIS) professionals deliver educational and lifelong learning and information services in a wide range of different disciplines. Library and information services are delivered by human subjects to human subjects. Accordingly, subjectivity in LIS services and education has become vital concern especially when the business model of library services has been shifted dramatically from Service Centered Model (SCM) to Customer Centered Model (CCM). Libraries have been transformed to focus on the library patrons by selecting their contents, services based on the community needs. Thus, subjectivity has become vital discipline to study and investigate in LIS education to focus more on quality rather than quantity. Consequently, qualitative research methodology has become important to implement within the LIS education community.

In quantitative research approach, researchers treat participants as objects that needed to be measured (Lichtman, 2006). Therefore, quantitative approach may fail to capture the participants' experiences, behavior, and perspectives (Lichtman, 2006). In contrast, qualitative researchers aim to explore the social world from the participants' perspectives to gain understanding (Astin\& Long, 2014). Since people hold different perspectives regarding certain situations, a qualitative researcher's aim is to capture the participants' perspectives through written or spoken words (Astin\& Long, 2014).

Qualitative research methods have common characteristics that distinguish them from quantitative methodology (Merriam, 2009). The common characteristics include (a) searching for the meaning of the participants' experiences to achieve understanding, (b) the researcher is the primary instrument in the research for data collection and analysis, (c) and the research process is inductive to build theories or concepts and not deductive to test hypotheses (Merriam, 2009).

\section{LIS Qualitative Research Designs}

Qualitative research has various designs such as phenomenological, ethnographic, case study, grounded theory among many other designs (Merriam, 2009). The researcher is compelled to choose the qualitative research design based on the purpose of the study. In phenomenological research design, the researcher aims to understand the meanings that constructed from simple unite of the participants' lived experiences. In ethnographic research design, the researcher aims to study the participants' culture and society through investigating their beliefs and values that shape their behaviors in a specific society (Merriam, 2009). In case study design, researcher aims to "investigate a contemporary phenomenon in depth and within its real-life context" (Yin, 2009, p. 18). In grounded theory design, the researcher aims to develop a theory that grounded in the field-based data that collected from the study participants and hold their perspectives regarding the phenomenon under study (Merriam, 2009).

\section{Sampling Frame in LIS Qualitative Research}

In qualitative research, sample of units needs to be selected to collect data for the research. Interviewing human subjects, visiting sites, observing activities, or collecting documents to read are the sample unites that researcher use to collect data for the study (Merriam, 2009). The sample types are varied based on the 
research's approach. In quantitative research approach, a probability sampling is needed as the researcher aims to generalize the results to a bigger population (Merriam, 2009). In qualitative research approach, however, nonprobability sampling is needed as the researcher aims to understand the phenomenon under study not to generalize the research results (Merriam, 2009).

A purposeful sample is a common type of non-probability sampling in qualitative research to serve as a rich source of data. The researcher determines the criteria that needed to select the purposeful sample that provides rich data units such as age groups, job description, or working sites (Merriam, 2009). The purposeful sample concerns with the quality over quantity as purposeful sample of two participants might collect rich data for a qualitative study such as narrative research (Creswell, 2013). Furthermore, Creswell (2013) asserted that the size of the selected sample is based on the type of the qualitative study and suggested a sample of 3 to 10 participants to collect data for phenomenological studies and 20 to 30 participants to collect enough data for grounded theory.

\section{Data Collection in LIS Qualitative Research}

In qualitative research approach, the researcher collects data from different sources based on the research design. In case study research design, Yin (2009) defines six sources of data that the researcher may use to collect data for the study. The data resources are (a) participant interview which is considered a primary source of data in qualitative research. Thus, open-ended, semi-structured interviews allow the participants to express their perspectives toward the phenomenon under study, (b) direct observation that allows the researcher to collect detailed data through observing a site or activities (c) participant observation which allows the researcher to collect the research data through observing the participants' activities (d) examine all documents that related to the phenomenon under study, (e) examine physical artifact related to the phenomenon under study, and (f) use the archival data related to the study (Yin, 2009). In phenomenological and grounded theory designs, the data needed for the study are collected from the participants' interviews only as the phenomenology research design focuses on capturing the participants' perspectives toward certain phenomenon based on lived experiences to obtain full description of the lived experiences under study (Merriam, 2008). However, grounded theory, however, moves beyond just obtaining a full description of the participants' lived experiences - such as phenomenological design- to developing a concept or a theory that grounded on the data collected from the participants' lived experiences (Creswell, 2013).

\section{Data Analysis and Presentation}

In qualitative research, the researcher examines the collected to data to identify themes and patterns (Irwin, 2013). Three data analysis strategies were defined by Creswell (2013) as follow: (a) organizing the data that collected from the interviews, observation notes, documents, and other sources, (b) formulating themes from the collected data, and (c) representing the results in tables, discussions, or figures. The researcher may use computer analysis software program such as Nvivo to identify themes that answer the research questions. NVivo assists researchers to (a) manage data that is collected from interviews, field notes, observations, and focus groups; (b) provide researchers with prompt access to generated conceptual information in the study; (c) provide a data query to retrieve all data relevant to questions and determine the answers; (d) create graphical models to explain the relationships between concepts that are built from the research data; and (e) create reports from the collected data (Bazeley, 2007)

The research data analysis and presentation is varied based on the qualitative research approach. In narrative research, the research data are analyzed based on the story told by the participant to identify the experiences. The researcher gathers the experiences to larger themes. Finally, the larger themes formulate factors that shaped the participant's life (Creswell, 2013). In phenomenological and grounded theory studies, the researcher describes the participant's personal experience regarding the phenomenon under study. Further, identify and group the substantial statements from the transcribed interviews to formulate themes in phenomenological studies and a theory in grounded theory studies. Subsequently, the researcher writes a textural description that describes the participant's experience with the phenomenon. Further, the researcher writes a structural description that elucidates the experience. Finally, combine both the textural and the structural descriptions to formulate a full description of the participant's experience with the phenomenon under study (Creswell, 2013). In case studies, the researcher reviews all the collected data from interviews, observations, and documents. Further, researcher initiates nodes and collect references from the collected data under each node which is called coding. Through collecting all data that related to each node, minor themes start to emerge. Similar minor themes will emerge to formulate the major themes to answer the research questions (Bazeley, 2007). 


\section{Comparing Qualitative Research Designs in LIS}

Qualitative research designs are similar in characteristics such the researcher is considered the primary instrument in research (Merriam, 2009). To conduct a qualitative research regardless of the approach, researcher has to follow the steps of: (a) develop research question related to the phenomenon under study, (b) identify a sample of participants appropriate for the study, (c) collect data for the study through observation or participants interviews, (d) transcribe interview to a textual format, and (e) analyze the collected data through coding, categorizing, and (f) present the study findings as a description (Phillips-Pula, Pickler \& Strunk, 2011). However, each design has different purpose. Thus, the researcher has to understand the differences between the qualitative designs in order to select the appropriate research design. This research aims to compare three research designs: (a) The phenomenological, (b) case study, and (c) grounded theory approaches based on the components needed for academic researches.

\section{The Purpose of Research in LIS Education}

Phenomenology as a philosophy was developed through the work of Husserl, Heidegger, MerleauPonte, Arendt, Sartre, Gadamer, and Levinas. However, Husserl is considered the founding father of the 'empirical philosophy' or 'practicing philosophy' that practiced the philosophy of phenomenology as a research method (Dowling, 2007; van Manen, 2007). Husserl transformed the phenomenology as a philosophical reflection on certain experience to identify philosophical problems to an empirical philosophical research that interact with people to obtain a description of their lived experiences (Dowling, 2007). Husserl's phenomenological approach called transcendental (descriptive) as the researcher aims to describe the phenomenon within the range of knowledge and without any interpretation (Dowling, 2007; Finlay, 2008).

For Heidegger, however, the phenomenological researcher aims to obtain meanings from the participants' lived experiences. The phenomenological research called hermeneutic (interpretive) as the research aims to obtain understanding. Thus, the researcher's thoughtful involvement is required in the research process (Vandermause\& Fleming, 2011).

Case study design is one of the challenging research designs in social research as the researcher uses the case study to gain knowledge regarding certain phenomenon in the real life context of the participants (Yin, 2009). Case study research has become a common a research in sociology, psychology, business, social science, and political science to understand the social phenomenon (Creswell, 2013; Yin, 2009). In case study design, the researcher has to identify the case that needed to be studied and in which context, and if it is single case or multiples cases (Creswell, 2013). The case study has four types of designs: (a) Explanatory case study that aims to answer a question that explains real-life situation that is complex to be answers through surveys or experimental methods (Baxter \& Jack, 2008), (b) Exploratory case study that used to explore certain phenomenon that has no clear outcomes (Yin, 2009), (c) descriptive case study that used to describe certain phenomenon in it real-life context where it is occurred (Yin, 2009), and (f) multiple case studies that aim to explore the differences between cases and replicate findings within cases (Yin, 2009).

Grounded theory is similar to phenomenological design as both designs aim to explore the lived experiences of study participants from their perspectives. Phenomenological design aims to develop a full description of the participants' lived experience (Moustakas, 1994). However, grounded theory design moves beyond description to develop theory (Cresewell, 2013). Grounded theorist state that theories are grounded in data that collected from the field during the process of people's interaction (Creswell, 2013).

Grounded theory research is categorized to: (a) classical grounded theory that based on the work of Glaser and Strauss $(1965,1967)$ that uses two types of data coding, substantive coding where the researcher analyze the data directly, and the theoretical coding where the researcher select the codes that saturate the core the theory, (b) Straussian's grounded theory which in this category, more procedures are added to code the structure the data, (c) constructive grounded theory which beliefs that the theory is not discovered but constructed and in contrast with the classical grounded theory approach, the constructive grounded theory determine the prior action within the area of interest through reviewing the literature first, and (d) feminist grounded theory that was developed for nurses to postmodern feminist epistemology is consistent with the grounded theory regarding the acknowledgment of multiple explanation of reality, theorist such as Judith Wuest in 1995 had advocated the use of combined elements from the three types of grounded theory and emerge them with the feminist theory. Accordingly, the feminist grounded theory is accepted as a research method in nursing profession when the research is focusing on women (Evans, 2013).

\section{Research Questions and Sampling Frame in LIS Education Research Questions}

Phenomenological research aims to obtain a full description of the participants' lived experiences regarding the phenomenon under study (Merriam, 2009; Moustakas, 1994). Accordingly, the research question used in qualitative phenomenological studies starts with 'what' to allow the participants describing their lived 
experiences from their perspectives (Merriam, 2009). Grounded theory is partially having similar process such as phenomenological approach in which the research question used to explore the participants' lived experiences starts with 'what', however, grounded theory moves beyond the description to develop concept or theory (Creswell, 2013)

Case study design is used in various research disciplines to explore, explain, or describe certain phenomenon (Yin, 2009). The researcher may select single case study or multiple-case studies and may study individuals, groups, or events (Creswell, 2013). Consequently, case study methodology entails the collection of different of information. Thus, case studies aim to answer a research questions that start with 'how' and 'why' (Yin, 2009).

\section{Sampling Frame and Saturation}

All qualitative approaches use the non-probability sampling as the researcher aims to discover and understand the phenomenon under study to resolve the research problem with no interest in generalizing the research results (Merriam, 2009). Purposeful sampling is a common type of non-probability sampling for qualitative research where the selected sample serves as a source of rich data about the phenomenon under study (Merriam, 2009). Purposeful sample size is ruled by quality over quantity as the researcher might collect rich data from small sample size of three participants if the researcher approached the participants in different ways, such as repeated interviews from different points (Koerber\& McMichael, 2008). The sample size is vary from research design to another based on the saturation of the data collected for the study. Cresewell (2013) suggested that a sample of 3 to 10 participants is enough to collect phenomenological studies. For grounded theory where more and repeated data are needed to form a theory, 20 to 60 participants are considerably a good sample size. Case study design depends on multiple sources of data such as observations, interviews, and documents. Thus, the sample will be varying based on the research's purpose and context (Crewswell, 2013).

\section{Data Collection for Qualitative Inquiry in LIS Education}

Phenomenological research approach aims to explore the participants' lived experiences from their perspectives (Merriam, 2009). Thus, the data needed for the study is collected through participants' interviews. Using semi-structured, open-ended questions interviews allow the participants to express their feelings and perceptions toward the phenomenon under study from their perspectives (Merriam, 2009).

In grounded theory design, the researcher follow the phenomenological design's procedure of collecting data for the study through interviewing the study participants using semi-structured, open-ended questions interviews. However, the researcher repeats the interviews with the participants to identify the core category needed to formulate the concept or the theory (Creswell, 2013).

In case study design, Yin (2009) defines six sources of data that the researcher may use to collect data for the study. The data resources are (a) participant interview which is considered a primary source of data in case study, (b) direct observation that allows the researcher to collect detailed data through observing a site or activities (c) participant observation which allows the researcher to collect the research data through observing the participants' activities (d) examine all documents that related to the phenomenon under study, (e) examine physical artifact related to the phenomenon under study, and (f) use the archival data related to the study (Yin, 2009).

\section{Data Analysis and Finding Presentation in LIS Education}

The most recognized phenomenological data analysis is van Kaam method of phenomenological data analysis outlined by Moustakas (1994):

1. The researcher lists every response related to the experience. This step is termed horizonalization.

2. Identify the invariant constituents. In this step, the researcher examines the responses searching for (a) if the response is relevant to the experience under study and contains an adequate element to gain understanding and (b) if the response can be labeled. All responses that are relevant to the experience under study and can be labeled are considered a horizon of the experience. All other responses that irrelevant to horizon of experience will be eliminated. Other repetitive, unclear, or overlapped responses will be also eliminated.

3. Clustering related invariant constituents into labeled themes. The clustered constituents will form the primary themes of the experience.

4. Validating the invariant constituents and the themes. In this step, the researcher will examine the themes against the researcher's transcribed data to determine if the invariant constituents and themes are (a) expressed clearly throughout the transcribed data, and (b) matching if not clearly expressed. If themes are not matching or clearly expressed, they are irrelevant to the experience under study and should be deleted.

5. The researcher will use the validated themes and invariant constituents to develop a rich textural-structured description of the meanings of the phenomenon under study for each participant. 
6. Combining the individual textural-structural description of the meanings of the experiences of each participant will allow the researcher to develop a description of the meanings of the phenomenon under study that represents the whole group (Moustakas, 1994).

In transcendent (descriptive) phenomenological design, the research findings are presented as full description of the phenomenon under study as portrayed by the study participants. However, in hermeneutic (interpretive) phenomenological design, the research findings are presented as unites of meanings that obtained from the researcher's understanding of the phenomenon under study (Vandermause \& Fleming, 2011).In grounded theory design, the researcher forms categories from the information that related to the phenomenon under study and called 'open coding'. In axial coding, however, the researcher form coding diagram that defines the central phenomenon and identifies the categories of conditions that affects the phenomenon and then identify the context of the conditions to formulate the concept or the theory (Crewswell, 2013). The research findings are presented as grounded concept of theory.In case studies, the researcher reviews all the collected data from interviews, observations, and documents. Further, researcher initiates nodes and collect references from the collected data under each node which is called coding. Through collecting all data that related to each node, minor themes start to emerge. Similar minor themes will emerge to formulate the major themes to answer the research questions (Bazeley, 2007). The research findings in case study design are presented as a detailed description of the case under study (Yin, 2009).

\section{Discussion}

\section{Trustworthiness Measures in LIS Qualitative Inquiry}

Lincoln and Guba (1985) described criteria to insure the trustworthiness of qualitative research in educational and human science research including sociology, psychology, and nursing. Validity and reliability criteria are used to judge the quality of quantitative inquiry to answer the essential question of how good is it? (Geelan, 2004). For example, the research's internal validity is concerned with 'truth vale' of the quantitative research findings (Geelan, 2004). Similarly, for qualitative research inquiry, Lincoln and Guba (1985) posit set of strategies to insure the trustworthiness of the inquiry. The first strategy is investigating the qualitative research's credibility, which is similar to investigating the internal validity in quantitative research. Credibility is concerned with study participants' representation of the phenomenon under study and their agreement to the study findings (Lincoln \& Guba, 1985).

\section{Credibility}

Lincoln and Guba (1985) suggested four approaches to improve qualitative research credibility:

1- Activities that support the study findings such as:

A. Spending enough time in the study field will increase the research credibility as the trust relationship will be developed between the study participants and the researcher.

B. Persistent observation to study participants and contemporary evidence that related to the phenomenon under study. The observation has to be supported through questioning the participants about their perspectives regarding the occurred phenomenon.

C. Triangulation provides qualitative studies with richness in data, which improve the research credibility. Triangulation has many forms such as (a) data triangulation where the researcher use multiple source of data, (b) methodology triangulation where the researcher uses multiple research methodology, (c) investigator triangulation where more than one investigator study the phenomenon, (d) theoretical triangulation where the researcher uses multiple theoretical perspectives (Lincoln \& Guba, 1985).

Triangulation is using multiple data sources to obtain conclusions. The use of multiple sources of data collection provides a comprehensive description of the phenomenon under study (Cope, 2004). Data collection methods include participants' interviews, site observation, participant observation, filed notes, and recording the research process in journaling format (Cope, 2004).

2- Peer debriefing is defined when the researcher shares the study with few professionals who are from the research community and interested in the study but not part of the study. Selected peers may question the research's methodology and theoretical framework that used in the study (Lincoln \& Guba, 1985).

3- Member checks is the process of (a) allowing the study participants to review and verify the data collected from interviews, participant-observations, and documentations to avoid the possibility of misinterpreting the collected data (Maxwell, 2005, Yin, 2009); and (b) after data analysis, the researcher meet with the study participants to review the conclusions and asks the participants to express whether they supported the study conclusions (Lincoln \& Guba, 1985).

4- Referential adequacy where part of the collected data of the qualitative study is stored as an archive while the rest of the collected data are analyzed. After developing the interpretations and categories from the larger data, the researcher examines the interpretations against the stored data and used as a referential 
adequacy to explain the rest of the stored data. This strategy is not adequate for small-scale studies; however, the strategy has a great potential to demonstrate the adequacy of the emergent category system to explain similar data (Geelan, 2004).

\section{Dependability}

Dependability in qualitative studies is related to the reliability in quantitative studies, which aims to ensure that different researcher can follow the researcher's trail in similar study (Cope, 2014). Dependability refers to the consistency of the data in different context with similar condition (Cope, 2014). Data consistency can be achieved when different researcher conducts same research in different context through following the researcher's process of conducting same research using similar participants within similar settings and the study findings were the same (Cope, 2014).To establish dependability, Lincoln and Guba (1985) suggested the inquiry audit technique that requires the involvement of a researcher who is not involved in the research to examine process of the conducted study. The process aims to evaluate the research accuracy through examining if the data support the study findings, conclusions, and interpretation (Amankwaa, 2016).An audit trail is the process to insure qualitative research dependability (Cope, 2014; Thomas \&Magilvy, 2011). The Audit trail process is as follow: (a) define the purpose of the study in detail; (b) discuss the study sampling frame and sampling criteria to explain how and why the study participants were selected; (c) discuss the data collection method and the time period needed to collect the data needed for the study; (d) discuss in detail the data analysis process used in the study; (e) discuss in detail the presentation and the interpretation of the study findings; and (f) discuss in detail the steps used to insure the data credibility in the study (Thomas \&Magilvy, 2011).

\section{Transferability}

Transferability in qualitative research is similar to the external validity in quantitative research (Thomas \&Magilvy, 2011). Research transferability is defined as the ability of transferring the research method or findings to another context (Thomas \&Magilvy, 2011). Lincoln and Guba (1985) defined research transferability as "how one determines the extent to which the findings of a particular inquiry have applicability in other contexts or with other subjects/participants" (p. 290). Finfgeld-Connett (2010) asserted that it is impossible for the researcher in naturalistic studies to anticipate in advance the extent in which the study findings will be transferable to another context. Accordingly, the researcher must provide thick responsive, thoughtful, and detailed description of the research's time and context in which another researcher can easily judge the research's applicability to be conducted in similar context (Thomas \&Magilvy, 2011).

The researcher achieved the thick description through describing the phenomenon under study in detail in which the conclusions can be transferred to other situation, settings, people, and times (Amankwaa, 2016). Merriam (2009) asserted that the researcher's responsibility is provide detailed information regarding the phenomenon under study to assist other researchers decide if the research results may or may not be applied to other settings. The researcher includes details such as study setting, climate, atmosphere, attitudes, and any other item that cannot be captured on audio recording

\section{Confirmability}

Thomas and Magilvy (2011) asserted that confirmability in qualitative research is similar to the objectivity in quantitative research. Further, the research's confirmability will be achieved when the credibility, dependability, and transferability of the research are established. Cope (2014) posits that research's confirmability is achieved when the researcher succeed in demonstrating that the data represent the participants' perspectives and responses and cleared from the researcher' biases. The reflexivity in qualitative researcher similar to construct validity in quantitative research - requires the researcher's knowledge regarding how preconceived notions affect the research. Accordingly, the researcher will record all personal feelings, thoughts, biases, and prior knowledge after each interview. Further, researcher should follow the research direction instead of leading the research direction by requesting the participants' clarification regarding their definitions and metaphors. Consequently, the researcher will conduct a reflective research by developing confirmability in which increased the research's trustworthiness and enhance the credibility of the research findings (Thomas \&Magilvy, 2011). Lincoln and Guba (1985) suggested three approaches to establish the confirmability of a qualitative research: (a) audit, (b) confirmability audit, (c) reflexivity, and (d) triangulation.

Linda and Guba suggested the researcher's use of reflective journal to insure the research's trustworthiness when following the techniques needed to enhance the credibility, dependability, transferability, and confirmability of the qualitative research inquiry (Amankwaa, 2016; Geelan, 2004). Reflective journal contains one or two pages journal to report the crises in the research or the critical incidents rather than write the journal in a diary style. Further, reflective journals contain reflective and thoughtful writing of questions that arise during conducting the research, research problem, and appropriate standard techniques that the researcher should apply, and ethical issues and concerns (Geelan, 2004).Geelan (2004) suggested set of standards for 
interpretive research as outlined by Lincoln and Guba and focus on interpretive research authenticity using the criteria of (a) educative that represent the extent in which the participants understand and appreciate the constructions of others, (b) fairness to ensure that the research results and process is obtained from the study participants not from the researcher, (c) ontological, (d) tactical authenticity, and (e) catalytic. The Ontological, catalytic and tactical authenticity are related to the participants' ability to (a) understand their situation in depth, and (b) to act accordingly to improve their situation. These standards focus on relationship and ethical research issues.

\section{References}

[1]. Amankwaa, L. (2016). Creating protocols for trustworthiness in qualitative research.Journal Of Cultural Diversity, 23(3), $121-127$.

[2]. Astin, F., \& Long, A. (2014).Characteristics of qualitative research and its application. British Journal Of Cardiac Nursing, 9(2), 93-98.

[3]. Baxter, P., \& Jack, S. (2008). Qualitative Case Study Methodology: Study Design and Implementation for Novice Researchers .The Qualitative Report, 13(4), 544-559.

[4]. Cope, D. G. (2014). Methods and meanings: Credibility and trustworthiness of qualitative research. Oncology Nursing Forum, 41(1), 89-91. doi:10.1188/14.ONF.89-91

[5]. Creswell, J.W. (2013). Qualitative inquiry and research design: Choosing among five approaches (3rd ed.). Thousand Oaks, CA: Sage Publication

[6]. Cutcliffe, J., \& McKenna, H. (1999).Establishing the credibility of qualitative research findings: the plot thickens.Journal Of Advanced Nursing, 30(2), 374-380. doi:10.1046/j.1365-2648.1999.01090.x

[7]. Dowling, M. (2007, January). From Husserl to van Manen.Areview of different phenomenological approaches. International Journal of Nursing Studies, 44(1), 131-142. doi:10.1016/j.ijnurstu.2005.11.026

[8]. Evans, G. (2013). A novice researcher's first walk through the maze of grounded theory: Rationalization for classical grounded theory. The Grounded Theory Review, 12(1), 37-55.

[9]. Finfgeld-Connett, D. (2010). Generalizability and transferability of meta-synthesis research findings. Journal Of Advanced Nursing, 66(2), 246-254. doi:10.1111/j.1365-2648.2009.05250.x

[10]. Finlay, L. (2008). A dance between the reduction and reflexivity: Explicating the "phenomenological psychological attitude". Journal Of Phenomenological Psychology, 39(1), 1-32. doi:10.1163/156916208X311601

[11]. Geelan, D.R. (2004). Weaving narrative nets to capture classrooms: Multimethod qualitative approaches for research in education. Dordrecht, Holland: Kluwer Academic Publishers.

[12]. Irwin, S. (2013). Qualitative secondary data analysis: Ethics, epistemology and context. Progress in Development Studies, 13, 295306. doi:10.1177/1464993413490479

[13]. Koerber, A., \& McMichael, L. (2008). Approaches and practice: Qualitative sampling methods. Journal of Business and Technical Communication, 22(4), 454-473. doi:10.1177/1050651908320362

[14]. Lichtman, M. (2006).Qualitative research in education: A user's guide. Thousand Oaks, CA: Sage.

[15]. Lincoln, Y. \& Guba, E. (1985).Naturalistic inquiry. Thousand Oaks, CA: SAGE Publications

[16]. Maxwell, J. A. (2005). Qualitative research design: An interactive approach (3rd ed.). Thousand Oaks, CA: Sage.

[17]. Merriam, S. (2009).Qualitative research: A guide to design and implementation. Revised and expanded from qualitative research and case study applications in education. San Francisco, CA: John Wiley \& Sons.

[18]. Moustakas, C. (1994). Phenomenological research methods.Thousand Oaks, CA: Sage.

[19]. Phillips-Pula, L., Pickler, R., \& Strunk, J. (2011, February). Understanding phenomenological approaches to data analysis. Journal of Pediatric Health Care, 25(1), 67-71. doi:10.1016/j.pedhc.2010.09.004

[20]. Thomas, E., \&Magilvy, J. K. (2011).Qualitative rigor or research validity in qualitative research.Journal For Specialists In Pediatric Nursing, 16(2), 151-155. doi:10.1111/j.1744-6155.2011.00283.x

[21]. Vandermause, R. K., \& Fleming, S. E. (2011). Philosophical Hermeneutic Interviewing. International Journal Of Qualitative Methods, 10(4), 367-377. Retrieved from

http://web.b.ebscohost.com.contentproxy.phoenix.edu/ehost/pdfviewer/pdfviewer?vid=7\&sid=2b9d487b-5c6a-4d08-be1a8595127 dd69c\%40sessionmgr111\&hid=125

[22]. Van Manen, M. (2007). Phenomenology of practice. Phenomenology \& Practice, 1(1), 11-30. Retrieved from http://www.maxvanmanen.com/files/2011/04/2007-Phenomenology-of-Practice.pdf

[23]. Yin, R. K. (2009).Case study research: Design and methods (4th ed.). Thousand Oaks, CA: Sage 